\title{
Face markings in Northern chamois: cues of dominance?
}

\author{
Luca Corlatti ${ }^{1} @$. Stefano Sivieri ${ }^{2}$
}

Received: 24 March 2020 / Accepted: 8 May 2020 / Published online: 8 June 2020

(c) The Author(s) 2020

\begin{abstract}
Black and white face markings in Artiodactyls are thought to be broadly associated with intraspecific communication. Evidence-based studies on the fine-scale mechanisms of signaling, however, are scant. The occurrence of black and white face markings is one of the most distinctive features of the Northern chamois Rupicapra rupicapra. Although their function is unknown, they might possibly signal fighting abilities: if so, the intensity of face color contrast should positively correlate with traits involved in aggressive contests, i.e. body mass and horn size. We collected data on face marking 'blackness' as a proxy of color contrast, dressed body mass and horn length on 103 chamois of either sex harvested during the hunting season of 2019 in the central Italian Alps. To investigate the relationship between color contrast and sex-specific body mass and horn length, we fitted an ordinal multilevel regression model in a Bayesian framework. Contrast score positively associated with increasing body mass in both sexes, but this relationship was much stronger in females than in males. Contrast score positively related with horn length in males but not in females. Our results offer some first insights into the potential correlates of chamois facial mask, suggesting that face markings might provide age-specific cues of mass-based dominance in females, while their role in males appears more uncertain. Behavioral studies on marked or hunted individuals in different environmental settings are necessary to confirm these findings, and provide further understandings of face color patterns in chamois.
\end{abstract}

Keywords Body mass $\cdot$ Coloration $\cdot$ Dominance $\cdot$ Face mask $\cdot$ Horns $\cdot$ Rupicapra

The overall coloration of mammals is determined by the combination of hair coloring and patterning, whose variation is typically explained by adaptive processes such as concealment, communication and regulation of physiological functions (Caro 2005). When the spatial distribution of pigmentation across the body is constrained, nonrandom coloration patterns arise (Caro and Mallarino 2020). Different selective pressures may account for color patterns in different body parts. Contrasting face colors, for example, may be selected for in interspecific communication, a notable example being the aposematic black and white color in

Handling editor: Francesco Ferretti.

Electronic supplementary material The online version of this article (https://doi.org/10.1007/s42991-020-00038-6) contains supplementary material, which is available to authorized users.

Luca Corlatti

luca.corlatti@wildlife.uni-freiburg.de

1 Chair of Wildlife Ecology and Management, University of Freiburg, Tennenbacher Str. 4, 79106 Freiburg, Germany

2 Istituto Oikos, Via Crescenzago 1, 21034 Milano, Italy some mustelids, which signals their unprofitability as prey (Newman et al. 2005). Colorful face ornaments may also play a role in intraspecific communication, for example in social cohesion, mate attraction or mate competition (Ancillotto and Mori 2017; Andersson 1994).

Artiodactyls show a wide array of coat colors, from uniform coloration to conspicuous dark or white patterns on different body parts such as face, legs, tail and rump (Stoner et al. 2003). In particular, black and white facial patterns are mostly found in species with diurnal habits, living in open areas and in intermediate-sized groups (Caro 2009), e.g. oryx Oryx spp., blackbuck Antilope cervicapra or pronghorn Antilocapra americana. This pattern may be explained by thermoregulation and/or intraspecific communication (Caro and Stankowich 2010). The white spots may reduce heat, while the black around the eyes may contrast sun's glare (cf. Caro 2011; Geist 1987). Size or brightness of black and white masks might possibly advertise ability to defend a territory (Caro 2009). More generally, if these color patterns signal dominance or condition, they may help settle disputes among opponents and reduce the costs of agonistic contests (Briffa 2014). 
The occurrence of black and white face markings is one of the most distinctive features of the Northern chamois Rupicapra rupicapra, a medium-size mountain ungulate native to central Europe and the near East (Corlatti et al. 2011). Chamois facial mask consists of white patches on both sides of the muzzle that extend to the neck and are separated by dark stripes running from the nose, through the eyes, to the base of the horns (Fig. 1). The function of this pattern is unknown, but it might involve social communication (cf. Stoner et al. 2003). Northern male chamois mainly interact competitively to secure mating, either through territoriality or female-following (Corlatti et al. 2012). During the November rut, both tactics frequently display aggressive postures such as lateral 'neck-up' (Fig. 2a) or frontal 'headdown' (Fig. 2b) towards another male or a female to herd back into the group (Krämer 1969; Lovari 1985; Corlatti et al. 2013). Similar information is scantier for Northern female chamois, but as in the Apennine subspecies Rupicapra pyrenaica ornata females also use aggressive 'side displays' (Fig. 2c) to assert dominance (Krämer 1969; Lovari 1985). Therefore, during aggressive contests, facial markings are kept well in evidence towards the opponent. Conversely, during courtship, Northern male chamois try to suppress aggressive responses by approaching females frontally with the 'head up' (Fig. 2d), a behavioral display that seemingly makes markings less conspicuous (Krämer 1969). These postures suggest that some facial marking characteristic, alongside other simultaneous displays, might be involved in attempts to assert dominance.

The main aim of this study was to assess the importance of color signals in chamois dominance. We suggest that the intensity of marking and white color contrast (hereafter 'face color contrast') may be an important component of a visual scene during intraspecific interactions, as achromatic color parameters are well perceptible to the chamois dichromatic visual system (Raveh et al. 2012; Fig. 1). If face markings aid in asserting dominance, positive relationships may occur between color contrast and other correlates of dominance. In chamois, body mass and horn length are traits that, to different extent, are thought to be involved in aggressive contests (females: Locati and Lovari 1991; males: Rughetti and Festa-Bianchet 2010a). During aggressive contests, for example, chamois overtly display body mass (Fig. 2a, c) and horns (Fig. 2b) towards the opponent. However, body mass in Northern chamois shows a greater coefficient of variation than horn length in both sexes (Rughetti and Festa-Bianchet $2010 \mathrm{a}, \mathrm{b})$, suggesting that horn length has a lower potential for selection; in turn, mass may be more important than horns to assert dominance. We therefore predict that the relationship of face color contrast with body mass should be stronger than with horn length in either sex.

The study site corresponds to the hunting district Verbano Cusio-Ossola (VCO2), which extends over $727 \mathrm{~km}^{2}$ in northern Piedmont, central Italian Alps $\left(46^{\circ} \mathrm{N}, 8^{\circ} \mathrm{E}\right)$. Data were collected from 87 females and 93 males between 1 and 16 years of age shot in $\mathrm{VCO} 2$ during the hunting season of 2019 (14 September-16 October). At the end of each hunting day, animals were collected to the checkpoint of the local hunting authority for indoor measurements, taken by the same person (SV). Face color contrast was approximated by a 'blackness' score assessed visually, on the shot animal, using a two-column color chart that contrasted white against a scale of grey. For each individual, contrast score could vary between 1 (white-light grey) and 8 (white-black). Score was assessed in the middle-front part of the muzzle, under similar artificial light conditions, and before other measurements were taken, to reduce potential bias in color perception. Other data included sex, age (in
Fig. 1 On the left, how chamois are seen by humans (trichromatic color vision); on the right, how chamois might see each other (dichromatic color vision). In both pictures the black and white contrast of facial mask is evident. The original picture on the left was converted using the red-blind dichromatic view option with the converter available at: https://www.colororacl e.org. The converted image is intended for illustration purposes only (Photo: Luca Corlatti)

Fig. 2 Lateral 'neck-up' (a) and frontal 'head-down' (b) postures used by male chamois during aggressive displays towards other males or females. Female 'side display' of dominance (c) and male 'head-up' frontal courtship posture (d) (Drawings: Luca Corlatti, modified from Krämer 1969)
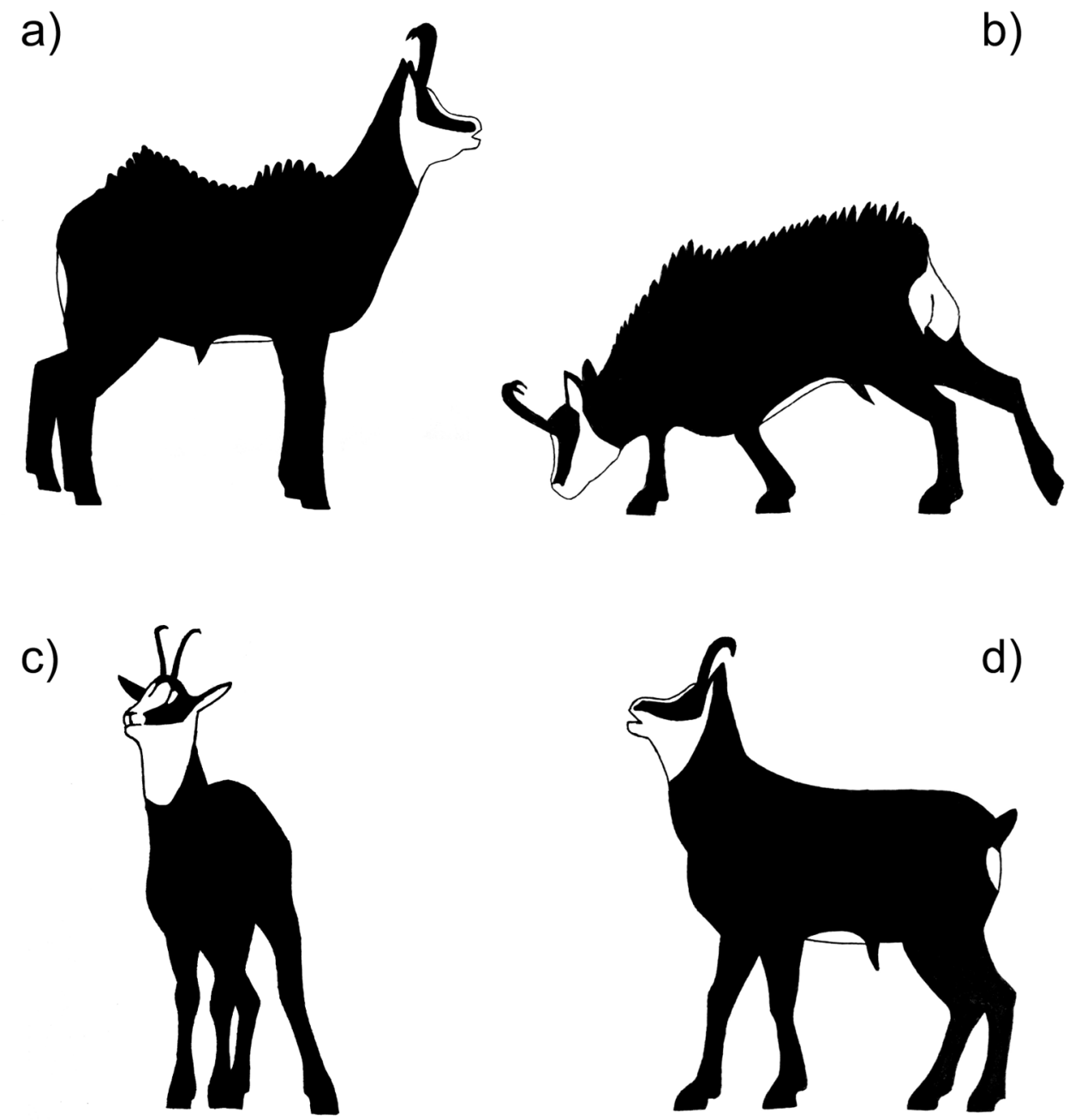

years, determined by counting the number of horn annuli: Schröder and von Elsner-Schack 1985), eviscerated body mass (in $\mathrm{kg}$, measured with a digital hanging scale, precision 0.1 ), total length of the longest horn (in $\mathrm{cm}$, measured with a flexible ruler, precision 0.1 ), hunting date and hunting location $(1 \times 1 \mathrm{~km}$ quadrant). Because some carcasses were fully eviscerated and some only partially eviscerated, the latter were corrected for the summed mass of heart, liver and/or lungs, to return comparable data.

Horn length and body mass in 1-year old chamois are partially compensated by growth in the next years (Rughetti and Festa-Bianchet 2010a), suggesting that their relationship with face color contrast might change after the 2 nd year of age. Furthermore, in our dataset, body mass and horn length were close to their asymptotic values from 2 and 3 years of age for females and males, respectively. To reduce potential bias, we thus excluded $<2$-year old females and $<3$-year old males from our analysis, and based our inference on a subset of 103 chamois ( $n=54$ females, $n=49$ males).

To investigate the relationships between color contrast score and its potential correlates, we fitted an ordinal regression model (Liddell and Kruschke 2018). Color contrast, an ordered categorical variable, was set as the response variable, while sex-specific total horn length and sex-specific eviscerated body mass were fitted as linear predictors. The covariates 'age at harvest' and 'Julian date of harvest' were included to control for the confounding effects of aging and seasonality on contrast score. Hunting location was fitted as a grouping factor to partly account for spatial effects on the response variable.

A Bayesian approach was used for inference. The joint posterior distribution of regression coefficients was estimated via Markov Chain Monte Carlo (MCMC) with 16000 sampling iterations over 4 chains, using the No-U-Turn Sampler (NUTS) (Hoffman and Gelman 2014). Flat priors were assumed for the effects of sex-specific horn length and body mass. Weakly informative priors were assumed for the regression coefficients of age (negative) and Julian date (positive), thus reflecting the fact that contrast score was expected to decrease with age but to increase over time, due to seasonal molting. Point estimates and credible intervals of regression coefficients were obtained from the means 
and the $2.5 \%$ and $97.5 \%$ quantiles of the posterior distribution of model parameters. Values of Evidence Ratio (ER), a measure of the strength of evidence in favor of one specific hypothesis over its alternative, were calculated to assess the probability that the relationships of horn length and body mass with face color contrast were greater than zero in both sexes. The marginal and conditional coefficients of determination $\left(R^{2}\right)$ were assessed following Gelman et al. (2019). Model fit was assessed through R-hat estimates, trace plots and posterior-predictive checks.

A detailed explanation of the statistical analysis is reported in Appendix 1 in ESM. The datafile used for analysis is available in Appendix 2 in ESM. All analyses were conducted with R 3.6.1 (R Core Team 2019) in RStudio 1.2.1335 (R Studio Team 2019). The package 'brms' (Bürkner 2017, 2018), a high-level interface to Stan (Carpenter et al. 2017), was used for MCMC analysis. The explained variance was assessed with the package 'performance' (Lüdecke et al. 2020), while the package 'shinystan' (Gabry 2018) was used for MCMC diagnostics.

There was no indication of convergence issues in the MCMC analysis, as suggested by the trace plots and the values of R-hat (all<1.02, cf. Brooks and Gelman 1998). The posterior-predictive checks suggested that the model predicted the actual response variable well. The fitted model explained about $64 \%$ of the conditional $R^{2}$ in color contrast score, while the conditional $R^{2}$ was about $30 \%$. The grouping effect of hunting location thus explained about $34 \%$ of the variance.

The relationship between face color contrast and total horn length was nearly flat in females, and positive in males (Table 1, Fig. 3). From the posterior distribution of model parameters, the probability that this relationship had values greater than zero was 0.53 in females (with evidence ratio [ER] of 1.2, i.e. this hypothesis was 1.2 times more likely than its alternative) and 0.94 in males $(\mathrm{ER}=16)$, while the probability that it was stronger in males than in females was
0.89 (ER = 8.1). Model estimates suggested that face color contrast related positively to body mass, but the relationship was stronger in females than in males (Table 1, Fig. 3). The probability that this relationship had values greater than zero was 1.00 in females $(E R=325.5)$ and 0.93 in males $(E R=14.2)$, while the probability that it was stronger in females than in males was $0.94(E R=14.7)$. As expected, age and seasonality had, respectively, negative and positive effects on face color contrast (Table 1).

Our results suggest that black and white color contrast positively associated with increasing body mass in either sex, but this relationship was much stronger in females than in males, possibly suggesting that face color contrast might act as an honest signal of female status. Conversely, contrast score showed some positive relationship with horn length in males but not in females. Insights into the importance of color signals in fighting abilities may be gained by investigating the relationship between coloration and sex-specific correlates of dominance.

In both sexes, body mass is overtly displayed during aggressive contests (Fig. 2a, c). In female chamois, body mass may provide cues of dominance (Locati and Lovari 1991). This, in turn is related with the ability to access foraging resources (Fattorini et al. 2018) which, in mountain ungulates, affects individual ability to sustain the energetic costs of gestation and lactation (Festa-Bianchet and Jorgenson 1998). Male-female body mass dimorphism in chamois largely increases before the rut (Rughetti and Festa-Bianchet 2011), suggesting that this trait might be under male-biased pressure of sexual selection. The seasonality of this pattern, however, suggests that sexual selection on males may be stronger on traits that favor direct forms of aggression, such as speed and agility (cf. Lovari 1984; Rughetti and FestaBianchet 2010a). Body mass might primarily (though not exclusively) be under pressure of natural selection, and its increase be selected to compensate energetic losses during the rut and maximize overwinter survival. Accordingly, the
Table 1 Model estimates for the relationship of total horn length, eviscerated body mass, sex, age at harvest, Julian date of hunting, sex-specific horn length and body mass with face color contrast in Alpine chamois

\begin{tabular}{lrcc}
\hline Parameter & Mean $\beta$ & \multicolumn{2}{l}{$95 \%$ credible interval } \\
\cline { 3 - 4 } & & $2.5 \%$ quantile & $97.5 \%$ quantile \\
\hline Males vs. females & -1.618 & -3.159 & -0.338 \\
Slope: horn length (females) & 0.037 & -0.666 & 0.750 \\
Slope: horn length (males) & 0.750 & -0.167 & 1.780 \\
Slope: body mass (females) & 1.535 & 0.398 & 2.932 \\
Slope: body mass (males) & 0.553 & -0.167 & 1.327 \\
Slope: age & -0.807 & -1.405 & -0.312 \\
Slope: Julian date & 0.455 & 0.067 & 0.921 \\
Slope: horn length $\times$ sex (males vs. females) & 0.708 & -0.386 & 1.971 \\
Slope: body mass $\times$ sex (males vs. females) & -0.983 & -2.411 & 0.267 \\
\hline
\end{tabular}

The table reports mean estimates of beta coefficients with lower and upper bounds of their $95 \%$ credible interval. Estimates of threshold coefficients (intercepts) are not shown 



Fig. 3 Marginal effects (with 95\% credible intervals) of the model fitted to investigate the relationships of face color contrast with sex-specific total horn length (left) and sex-specific eviscerated body mass (right) in 103 adult individuals of Alpine chamois

relationship between contrast score and male body mass was not particularly strong, as it would take about $15 \mathrm{~kg}$ for a male to gain only 1 point in color contrast (Fig. 3). Thus, if variation in color signals provides information about age-specific differences in body mass, increasing contrast in chamois face mask may provide cues of dominance in females, while in males it might possibly signal other characteristics, such as better physical conditions or better fighting abilities (cf. Andersson 1994).

Although horns are overtly displayed during aggressive contests (Fig. 2b), long weapons do not seem to confer great reproductive advantages in either sex of the Northern chamois (Corlatti et al. 2015a, b; Rughetti and Festa-Bianchet 2010a). In turn, horn length seems unlikely to play a major role in intraspecific communication. Although information on the relationship between coloration and horn size is scant, Falchetti et al. (1994) suggest that white spots in the neck and horn area of adult Nile lechwe Kobus megaceros make for an easy assessment of horn size, thereby emphasizing threats displays and reducing male-male competition. The stronger effect found in males than in females suggests that chamois horn length may play a relatively greater role in the former than in the latter during intrasexual contests (cf. Douhard et al. 2020). This suggestion may not hold for other chamois subspecies, notably the Apennine chamois, where horns are well developed and may provide cues of dominance in both sexes (cf. Locati and Lovari 1991).

In more advanced Caprinae such as wild sheep and goats, male agonistic behavior is highly ritualized and largely based on clash and butt behaviors, which are supported by a strong development in body mass and horn size (Schaller 1977).
Conversely, chamois have a less ritualized behavior that relies more blandly on physical features: chamois forms are rather primitive, with a limited sexual dimorphism and small weapons which, however, make physical contacts potentially dangerous (cf. Corlatti et al. 2013). Although chamois social contests seem to rely only to a limited extent on sex-specific body mass and weapon size, the positive correlations of face color contrast with some of these traits suggests that face markings might aid in asserting dominance. If so, face markings might help individuals to settle contests without escalating to a fight, thereby reducing the risks of physical contacts (Archer 1988) and the need for energy-consuming aggressive interactions (cf. Briffa 2014). Likewise, in the Himalayan tahr Hemitragus jemlahicus, an intermediate caprid with strong body mass dimorphism, limited horn size and non-ritualized fighting behavior, mane color signals rank hierarchy in male-male aggressive interactions (Lovari et al. 2009, 2015). Lighter-colored male tahr are dominant over darker-colored males and, somewhat similarly to the chamois, the contrast between black face and golden mane may be emphasized via frontal-oriented threat displays used mostly by top-ranking individuals (Lovari et al. 2015).

The interpretation of our results requires caution. The estimation of contrast score was based on the variation in face mask blackness, intrinsically assuming consistency in whiteness. This arguably coarse estimation, however, allowed to capture the expected change in color contrast with increasing age and Julian date, thereby suggesting that our data had sufficient power to reflect actual variance in color contrast. The negative relationship between color contrast and age supports the fact that facial stripes 
become progressively paler with increasing age. This, however, should not be interpreted as a sign of steady decline of dominance with age: face color contrast may be just one of several cues of dominance, as adult chamois prevail over young (Corlatti et al. 2015a, b) and, possibly, old individuals (Locati and Lovari 1991), for example because they may have greater experience, or larger body mass. In our model, the effect of body mass and horn size on color contrast was adjusted by age, meaning that these relationships are best interpreted within the frame of different age classes: for example, heavier subadult females (c. 2-3 years old) may be more dominant (i.e. have darker stripes) than lighter subadult females, and heavier adult females (c. 4-7 years old) may be more dominant (i.e. have darker stripes) than lighter adult females. Although subadult females might have darker stripes than adult females, this would not necessarily make them dominant, because adult females would be generally heavier and more experienced. The period of data collection may also have consequences on the interpretation of results. In September-October, chamois seasonal molting is at its intermediate stage (Couturier 1938). It would be important to assess whether the observed relationships of contrast score with body mass and horn length persist in periods when competition for food (e.g. summer, for females) or mates (November, for males) is strongest. We also acknowledge that, in chamois, investment in life history traits such as body mass and horn length varies depending on environmental features (Mason et al. 2011), thus the relationship between face color contrast and morphology might change accordingly. In addition, investigations should be extended to other chamois species and subspecies, which show different patterns of horn growth and coloration.

Acknowledgements Open Access funding provided by Projekt DEAL. We are grateful to the hunters of the Comprensorio Alpino Verbano Cusio-Ossola for their support during data collection, to Roberto Viganò for providing correction factors for partially eviscerated body mass and to Simone Tenan for his comments on the description of Bayesian regression in Appendix 1. We thank Marco Festa-Bianchet and Niccolò Fattorini for their thoughtful comments and efforts towards improving our manuscript.

Author contributions LC conceived the idea for this work, did the statistical analyses and wrote all drafts of the manuscript. SV collected the data and participated in writing up the manuscript.

Funding Not applicable.

Availability of data and material Data used for analyses are available in Appendix 2. Code availability: Codes used for analyses are available in Appendix 1.

\section{Compliance with ethical standards}

Conflict of interest We have no conflict of interest to declare.
Ethics approval The data used in this analysis come from hunting activity legally authorized in accordance with the Italian law n. 157/92.

Open Access This article is licensed under a Creative Commons Attribution 4.0 International License, which permits use, sharing, adaptation, distribution and reproduction in any medium or format, as long as you give appropriate credit to the original author(s) and the source, provide a link to the Creative Commons licence, and indicate if changes were made. The images or other third party material in this article are included in the article's Creative Commons licence, unless indicated otherwise in a credit line to the material. If material is not included in the article's Creative Commons licence and your intended use is not permitted by statutory regulation or exceeds the permitted use, you will need to obtain permission directly from the copyright holder. To view a copy of this licence, visit http://creativecommons.org/licenses/by/4.0/.

\section{References}

Ancillotto L, Mori E (2017) Adaptive significance of coat colouration and patterns of Sciuromorpha (Rodentia). Ethol Ecol Evol 29:241-254

Andersson M (1994) Sexual selection. Princeton University Press, Princeton

Archer J (1988) The behavioural biology of aggression. Cambridge University Press, New York

Briffa M (2014) Agonistic signals: integrating analysis of functions and mechanisms. In: Irschick DJ, Briffa M, Podos J (eds) Animal signaling and function: an integrative approach. Wiley, Hoboken, pp 141-173

Brooks S, Gelman A (1998) General methods for monitoring convergence of iterative simulations. J Comput Graph Stat 7:434-455

Bürkner P-C (2017) brms: an R package for Bayesian multilevel models using Stan. J Stat Softw 80:1-28

Bürkner P-C (2018) Advanced Bayesian multilevel modeling with the R package brms. R J 10:395-411

Caro $\mathrm{T}$ (2005) The adaptive significance of coloration in mammals. Bioscience 55:125-136

Caro T (2009) Contrasting coloration in terrestrial mammals. Philos Trans R Soc B Biol Sci 364:537-548

Caro T (2011) The functions of black-and-white coloration in mammals: review and synthesis. In: Stevens M, Merilaita S (eds) Animal Camouflage: mechanisms and function. Cambridge University Press, Cambridge, pp 298-329

Caro T, Mallarino R (2020) Coloration in mammals. Trends Ecol Evol 35:357-366

Caro T, Stankowich T (2010) The function of contrasting pelage markings in artiodactyls. Behav Ecol 21:78-84

Carpenter B, Gelman A, Hoffman MD, Lee D, Goodrich B, Betancourt M, Brubaker M, Guo J, Li P, Riddell A (2017) Stan: a probabilistic programming language. J Stat Softw 76:1-32

Corlatti L, Lorenzini R, Lovari S (2011) Conservation of the chamois Rupicapra spp. Mammal Rev 41:163-174

Corlatti L, Béthaz S, von Hardenberg A, Bassano B, Palme R, Lovari $S$ (2012) Hormones, parasites and male mating tactics in Alpine chamois: Identifying the mechanisms of life history trade-offs. Anim Behav 84:1061-1070

Corlatti L, Caroli M, Pietrocini V, Lovari S (2013) Rutting behaviour of territorial and nonterritorial male chamois: is there a home advantage? Behav Proc 92:118-124

Corlatti L, Bassano B, Polakova R, Fattorini L, Pagliarella M, Lovari $S$ (2015a) Preliminary analysis of reproductive success in a large 
mammal with alternative mating tactics, the Alpine chamois, Rupicapra r. rupicapra. Biol J Lin Soc 116:117-123

Corlatti L, Gugiatti A, Imperio S (2015b) Horn growth patterns in Alpine chamois. Zoology 118:213-219

Couturier M (1938) Le chamois. Arthaud, Grenoble

Douhard M, Crampe J-P, Loison A, Bonenfant C (2020) A negative association between horn length and survival in a weakly dimorphic ungulate. Ecol Evol 10:2793-2802

Falchetti E, Ceccarelli A, Mantovani C (1994) Relationship between dominance/subordination and colouring patterns in Kobus megaceros (Bovidae, Reduncinae) captive males. Italian J Zool 61(S1):68-68

Fattorini N, Lovari S, Brunetti C, Baruzzi C, Cotza A, Macchi E, Pagliarella MC, Ferretti F (2018) Age, seasonality, and correlates of aggression in female Apennine chamois. Behav Ecol Sociobiol $72: 171$

Festa-Bianchet M, Jorgenson JT (1998) Selfish mothers: reproductive expenditure and resource availability in bighorn ewes. Behav Ecol 9:144-150

Gabry J (2018) shinystan: Interactive visual and numerical diagnostics and posterior analysis for Bayesian models. R Package Version 2.5.0. https://CRAN.R-project.org/package=shinystan

Geist V (1987) On the evolution of optical signals in deer: a preliminary analysis. In: Wemmer CM (ed) Biology and management of the Cervidae. Smithsonian Institution Press, Washington, DC, pp 235-255

Gelman A, Goodrich B, Gabry J, Vehtari A (2019) R-squared for Bayesian regression models. Am Statist 73:307-309

Hoffman MD, Gelman A (2014) The No-U-Turn sampler: adaptively setting path lengths in Hamiltonian Monte Carlo. J Mach Learn Res 15:1593-1623

Krämer A (1969) Soziale Organisation und Sozialverhalten einer Gemspopulation (Rupicapra rupicapra L.) der Alpen. Zeitschrift für Tierpsychol 26:890-964

Liddell TM, Kruschke JK (2018) Analyzing ordinal data with metric models: what could possibly go wrong? J Exp Soc Psychol 79:328-348

Locati M, Lovari S (1991) Clues for dominance in female chamois: age, weight, or horn size? Aggressive Behav 17:11-15

Lovari S (1984) Il popolo delle rocce. Rizzoli Editore, Milan

Lovari S (1985) Behavioural repertoire of the Abruzzo chamois, Rupicapra pyrenaica ornata Neumann, 1899 (Artiodactyla: Bovidae). Säugetierkundliche Mitteilungen 32:113-116
Lovari S, Fattorini N, Boesi R, Bocci A (2015) Male ruff colour as a rank signal in a monomorphic-horned mammal: behavioural correlates. Sci Nature 102:39

Lovari S, Pellizzi B, Boesi R, Fusani L (2009) Mating dominance amongst male Himalayan tahr: blonds do better. Behav Proc 81:20-25

Lüdecke D, Makowski D, Waggoner P, Patil I (2020) Performance: assessment of regression models performance. $\mathrm{R}$ package version 0.4.5. https://CRAN.R-project.org/package=performance

Mason THE, Chirichella R, Richards SA, Stephens PA, Willis SG, Apollonio M (2011) Contrasting life histories in neighbouring populations of a large mammal. PLoS ONE 6:e28002

Newman C, Buesching CD, Wolff JO (2005) The function of facial masks in 'midguild' carnivores. Oikos 108:623-633

R Core Team (2019) R: A language and environment for statistical computing. Vienna, Austria: R foundation for statistical computing. https://www.R-project.org/

R Studio Team (2019) RStudio: integrated development for R. RStudio Inc, Boston

Raveh S, van Dongen WFD, Grimm C, Ingold P (2012) Cone opsins and response of female chamois (Rupicapra rupicapra) to differently coloured raincoats. Eur J Wildl Res 58:811-819

Rughetti M, Festa-Bianchet M (2010a) Compensatory growth limits opportunities for artificial selection in Alpine chamois. J Wildl Manag 74:1024-1029

Rughetti M, Festa-Bianchet M (2010b) Effects of early horn growth on reproduction and hunting mortality in female chamois. J Anim Ecol 80:438-447

Rughetti M, Festa-Bianchet M (2011) Seasonal changes in sexual-size dimorphism in northern chamois. J Zool 284:257-264

Schaller GB (1977) Mountain monarchs. The University of Chicago Press, Chicago

Schröder W, von Elsner-Schack IV (1984) Correct age determination in chamois. In: Lovari S (ed) The biology and management of mountain ungulates. Croom Helm, London, pp 67-70

Stoner CJ, Caro TM, Graham CM (2003) Ecological and behavioral correlates of coloration in artiodactyls: systematic analyses of conventional hypotheses. Behav Ecol 14:823-840

Publisher's Note Springer Nature remains neutral with regard to jurisdictional claims in published maps and institutional affiliations. 